\title{
固体・液体表面の3次元形状計測法の開発
}

\section{Image measurements of three-dimensional shapes of solid objects and liquid free-surfaces}

\author{
渡部靖憲 $^{1}$. 三戸部佑太 ${ }^{2}$

\section{Yasunori WATANABE and Yuta MITOBE}

\begin{abstract}
This paper presents the novel imaging technique for localizing the surfaces of solid objects and the liquid freesurface in three-dimensional space. In this method, colour grids, projected from a PC projector, illuminating the surface of object, is recorded by a digital camera to specify the relative relation of the projector and camera coordinates for the grid locations. The shape of the object can be estimated from a pin-hole model for the determined relation. This system was found to be capable of measuring the three-dimensional coordinates of any solid surfaces at high accuracy with mean error less than $0.1 \mathrm{~mm}$ through a series of verifications.
\end{abstract}

\section{1. はじめに}

本研究は, プロジェクター照明下の任意物体を 1 台のデ ジタルカメラで撮影することにより, その3次元表面形状 の座標を計測する新たな画像計測システムを提案するも のである. 本開発システムは, 海岸工学において研究か ら施工に至るまでの広い分野において適用可能な有用な 3 次元計測ツールとなるポテンシャルを有する. 即ち, 回 折, 屈折波等3次元性波浪の面的計測, 消波ブロック等の 飛散状況の数值化, 船体動摇試験における船体自体の3 次 元形状座標の追跡さらには, 汀線管理の数值的評価, 被 災時の複雑な構造物変位など, 物体あるいは液体の表面 3 次元形状を数值的に取得可能となれば作業の合理化, 定 量的評価，管理の高度化に大きく寄与すると考える.

本研究で提案する計測法は, 既に商品化されている2台 のカメラによるステレオグラム法とは異なり, 画像相関 によるマッチングを必要としないため光学的環境に依存 せず，また撮影画像パターンが変化しない物体に対して も高精度で体積的な 3 次元座標を取得可能とする極めて有 用なものである。本研究では提案する計測アルゴリズム を説明すると共に, 多様な物体, 液体表面形状の計測を 通してその信頼性と有効性を検証する.

\section{2. 計測アルゴリズム}

本計測法では, 既知である投影カラー座標を PCプロジ エクターにより物体に照射し, 物体表面で反射するカラ 一座標を 1 台のデジタルカメラによって撮影する。図-1に 示すように, カメラ及びプロジェクター両者についてピ ンホールモデルを適用し, カメラ座標の原点 $O_{c}\left(o_{c x}, o_{c y}, o_{c z}\right)$, プロジェクター座標の原点 $O_{p}\left(o_{p x}, o_{p y}, o_{p z}\right)$ として, それぞ れ対象とする物体上の点 $M(X, Y, Z)$ を投影する画像座標平

$\begin{array}{lll}1 & \text { 正会員 博 (工) } & \begin{array}{l}\text { 北海道大学准教授大学院工学研究科 } \\ 2 \text { 学生会員 }\end{array} \\ & \text { 北海道大学大学院工学研究科 }\end{array}$

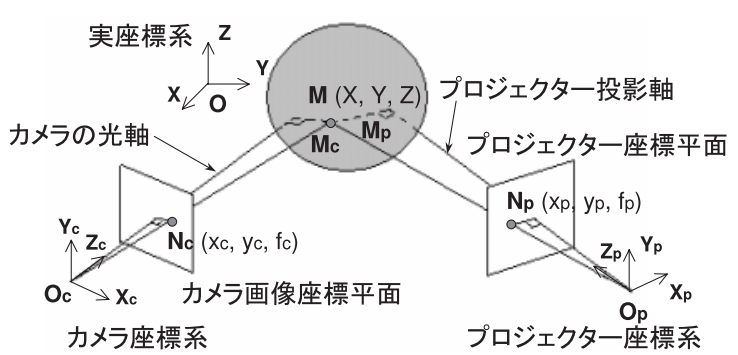

図-1 ピンホールモデルと座標系

面を考える. カメラ座標系における物体上の点 $M_{c}$ の座標 と $M_{c}$ が撮影画像に投影された点 $N_{c}$ の座標の間には, その 奥行きの比から次の関係が成り立つ.

$$
x_{c}=f_{c} \frac{X_{c}}{Z_{c}}, y_{c}=f_{c} \frac{Y_{c}}{Z_{c}}
$$

ただし， $\left(X_{c}, Y_{c}, Z_{c}\right)$ を $M_{c},\left(x_{c}, y_{c}, f_{c}\right)$ を $N_{c}$ のカメラ座標と する.ここで, $f_{c}$ はカメラの焦点距離である. 幾何学的関 係から, 次式を得る.

$$
\overrightarrow{O_{c} N_{c}}=\frac{f_{c}}{\overrightarrow{O_{c} M_{c}} \cdot \overrightarrow{k_{c}}} \overrightarrow{O_{c} M_{c}}
$$

ここで, $\overrightarrow{k_{c}}=\left(k_{c x}, k_{c y}, k_{c z}\right)$ はカメラの光軸方向単位ベクト ルである. 式（2）の両辺とカメラ座標系における水平方 向単位ベクトル $\overrightarrow{i_{c}}=\left(i_{c x}, i_{c y}, i_{c z}\right)$ および鉛直方向単位べクト ル $\overrightarrow{j_{c}}=\left(j_{c x}, j_{c y}, j_{c z}\right)$ との内積をとると,

$$
\begin{aligned}
& \overrightarrow{O_{c} N_{c}} \cdot \overrightarrow{i_{c}}=\frac{f_{c}}{\overrightarrow{O_{c} M_{c}} \cdot \overrightarrow{k_{c}}} \overrightarrow{O_{c} M_{c}} \cdot \overrightarrow{i_{c}}=x_{c} \\
& \overrightarrow{O_{c} N_{c}} \cdot \overrightarrow{j_{c}}=\frac{f_{c}}{\overrightarrow{O_{c} M_{c}} \cdot \overrightarrow{k_{c}}} \overrightarrow{O_{c} M_{c}} \cdot \overrightarrow{j_{c}}=y_{c}
\end{aligned}
$$

同様にプロジェクター座標系において，投影画像上の 点 $N_{p}$ とそれが物体上に投影された点 $M_{p}$ の座標の間には次 の関係が成り立つ.

$$
\overrightarrow{O_{p} N_{p}} \cdot \overrightarrow{i_{p}}=\frac{f_{p}}{\overrightarrow{O_{p} M_{p}} \cdot \overrightarrow{k_{p}}} \overrightarrow{O_{p} M_{p}} \cdot \overrightarrow{i_{p}}=x_{p}
$$




$$
\overrightarrow{O_{p} N_{p}} \cdot \overrightarrow{j_{p}}=\frac{f_{p}}{\overrightarrow{O_{p} M_{p}} \cdot \overrightarrow{k_{p}}} \overrightarrow{O_{p} M_{p}} \cdot \overrightarrow{j_{p}}=y_{p}
$$

ここで $\overrightarrow{i_{p}}=\left(i_{p x}, i_{p y}, i_{p z}\right), \overrightarrow{j_{p}}=\left(j_{p x}, j_{p y}, j_{p z}\right), \overrightarrow{k_{p}}=\left(k_{p x}, k_{p y}, k_{p z}\right)$ は プロジェクター座標系における各方向単位べクトルであ る. $M_{c}$ および $M_{p}$ が計測対象上の同一点 $M(X, Y, Z)$ である 場合, 式（3）は次のように変形できる.

$$
\begin{aligned}
X\left(x_{c} k_{c x}-f_{c} i_{c x}\right)+Y\left(x_{c} k_{c y}-f_{c} i_{c y}\right) \\
+Z\left(x_{c} k_{c z}-f_{c} i_{c z}\right)=x_{c}\left(\overrightarrow{O_{c}} \cdot \overrightarrow{k_{c}}\right)-f_{c}\left(\overrightarrow{O_{c}} \cdot \overrightarrow{i_{c}}\right)
\end{aligned}
$$

同様に式 (4)，（5），(6) を変形し，次の連立式を得る.

$$
T \boldsymbol{X}=\boldsymbol{B}
$$

ただし，

$$
\begin{aligned}
\boldsymbol{X} & =\left(\begin{array}{lll}
X & Y & Z
\end{array}\right)^{T} \\
\boldsymbol{T} & =\left(\begin{array}{lll}
x_{c} k_{c x}-f_{c} i_{c x} & x_{c} k_{c y}-f_{c} i_{c y} & x_{c} k_{c z}-f_{c} i_{c z} \\
y_{c} k_{c x}-f_{c} j_{c x} & y_{c} k_{c y}-f_{c} j_{c y} & y_{c} k_{c z}-f_{c} j_{c z} \\
x_{p} k_{p x}-f_{p} i_{p x} & x_{p} k_{p y}-f_{p} i_{p y} & x_{p} k_{p z}-f_{p} i_{p z} \\
y_{p} k_{p x}-f_{p} j_{p x} & y_{p} k_{p y}-f_{p} j_{p y} & y_{p} k_{p z}-f_{p} j_{p z}
\end{array}\right) \\
\boldsymbol{B} & =\left(\begin{array}{ll}
x_{c}\left(\overrightarrow{O_{c}} \cdot \overrightarrow{k_{c}}\right)-f_{c}\left(\overrightarrow{O_{c}} \cdot \overrightarrow{i_{c}}\right) \\
y_{c}\left(\overrightarrow{O_{c}} \cdot \overrightarrow{k_{c}}\right)-f_{c}\left(\overrightarrow{O_{c}} \cdot \overrightarrow{j_{c}}\right) \\
x_{p}\left(\overrightarrow{O_{p}} \cdot \overrightarrow{k_{p}}\right)-f_{p}\left(\overrightarrow{O_{p}} \cdot \overrightarrow{i_{p}}\right) \\
y_{p}\left(\overrightarrow{O_{p}} \cdot \overrightarrow{k_{p}}\right)-f_{p}\left(\overrightarrow{O_{p}} \cdot \overrightarrow{j_{p}}\right)
\end{array}\right)
\end{aligned}
$$

行列 $\boldsymbol{T}$ および $\boldsymbol{B}$ に含まれる值のうち， $\left(x_{c}, y_{c}\right),\left(x_{p}, y_{p}\right)$ は プロジェクターから既知の投影座標をもつカラーグリッ ドを投影し，それをカメラで撮影し画像座標で特定でき るため, 既知となる。残りの未知数であるプロジェク夕 一座標系の各方向単位ベクトル, 原点の実座標, 焦点距 離を次に説明するキャリブレーションによって取得すれ ば，式（8）の最小二乗解として，物体表面の3次元座標 $X$ を算出することが可能である.

キャリブレーションでは, 予め実座標が既知である複 数の格子にカラー座標を照射し, 格子上に投影されたカ ラー座標をカメラで撮影する.プロジェクター光軸上の 任意の複数の異なる位置の実座標並びに任意のカラー座 標の実座標が与えられれば，プロジェクターの投影軸方 向単位ベクトル $\overrightarrow{k_{p}}$ 及びプロジェクター座標系の原点 $O_{p}$ の 実座標が決定できる. カメラ座標系についても同様に，力 メラの光軸方向単位ベクトル $\overrightarrow{k_{c}}$ およびカメラ座標原点 $O_{c}$ の実座標を求めることが可能である.

次にカメラ座標系およびプロジェクター座標系におけ る水平方向単位ベクトル $\vec{i}$, 鉛直方向単位ベクトル $\vec{j}$, 焦 点距離 $f$ を求める. まず,

$$
\overrightarrow{\mathrm{P}}=\left(P_{x}, P_{y}, P_{z}\right)=\frac{\overrightarrow{\mathrm{O}_{\mathrm{c}} \mathrm{M}_{\mathrm{c}}}}{\overrightarrow{\mathrm{O}_{\mathrm{c}} \mathrm{M}_{\mathrm{c}}} \cdot \overrightarrow{\mathrm{k}_{\mathrm{c}}}}
$$

とおくと, 式（3）は次のように変形できる.

$$
x_{c}=P_{x} f_{c} i_{c x}+P_{y} f_{c} i_{c y}+P_{z} f_{c} i_{c z}
$$

上式の最少自乗和及びカメラの光軸方向単位ベクトル $\overrightarrow{k_{c}}$ と水平方向単位ベクトル $\overrightarrow{i_{c}}$ の直交条件

$$
\overrightarrow{i_{c}} \cdot \overrightarrow{k_{c}}=i_{c x} k_{c x}+i_{c y} k_{c y}+i_{c z} k_{c z}=0
$$

に対して次式を得る.

$$
\left(\begin{array}{ccc}
\sum P_{x}^{2} & \sum P_{x} P_{y} & \sum P_{z} P_{x} \\
\sum P_{x} P_{y} & \sum P_{y}^{2} & \sum P_{z} P_{x} \\
\sum P_{z} P_{x} & \sum P_{y} P_{z} & \sum P_{z}^{2} \\
k_{c x} & k_{c y} & k_{c z}
\end{array}\right)\left(\begin{array}{c}
f_{c} i_{c x} \\
f_{c} i_{c y} \\
f_{c} i_{c z}
\end{array}\right)=\left(\begin{array}{c}
\sum x_{c} P_{x} \\
\sum x_{c} P_{y} \\
\sum x_{c} P_{z} \\
0
\end{array}\right) \cdots
$$

上式において $\left(P_{x}, P_{y}, P_{z}\right), x_{c}$ はキャリブレーションの際 は既知であり $, f_{c} i_{c x}, f_{c} i_{c y}, f_{c} i_{c z}$ の最小二乗解を求めること で， $f_{c}$ および $\overrightarrow{i_{c}}$ を求めることができる. 同様の計算を行 うことで, $\overrightarrow{j_{c}}, \overrightarrow{i_{p}}, \overrightarrow{j_{p}}, f_{p}$ のデータを取得する.

\section{3. 実験方法}

本計測法ではカラー座標としてカラーパターン（図-2参 照）を物体に投影し，物体表面で反射した各ブロックの 重心の画像座標を入力值として与える。このカラーパタ ーンは，隣接する色が全て異なるように配置されており， 複雑な形状の物体表面で反射した場合でも，任意のブロ ックのプロジェクタ座標を特定することができる．各ブ ロックは，画像座標上でブロック形状が十分解像でき重 心を算出することができるサイズである必要があり，か つ対象物体の形状変化の長さスケールより小さくする必 要がある. 撮影されるブロックサイズは, プロジェク夕 及びカメラと対象物体までの距離, 及び物体の変形度合 に依存するため, 撮影環境及び対象物体に応じて撮影画 像を確認する必要がある。また，プロジェク夕の投影光 の強度は, プロジェクタからの距離の2乗に反比例して減 衰するため, 計測領域を大きくするためには高出力のプ ロジェクタが必要である.

デジタルカメラにより撮影されたカラー座標は, 撮影 画像における各ピクセルのRGB值を $\mathrm{L}^{*} \mathrm{a} * \mathrm{~b}$ *值に変換する ことによりカラー抽出を行いその座標を特定した． $\mathrm{L}^{*}$, $a^{*}, b^{*}$ はそれぞれ色の明るさ，緑-赤方向の色合い，青-黄 方向の色合いを表す值であり，これら3つの值による色の 表現は人間の色覚に近いとされ，色を識別する処理に多 く用いられている. 一般に光の反射強度は, 物体の光の 吸収スペクトルに依存する。即ち，高い吸収スペクトル のレンジの色は反射され難いため，材質に応じて投影し た色が抽出できない可能性がある。これについては，対 象物の材質に応じた投影色の変更が必要となるが，本研 究で対象とした反射率の高い白色のコンクリートでは, 色 に依存する反射強度の低下はみられなかった。

本研究では, 直方体ブロック，模型消波ブロック等の 固体および造波水槽における水面形の動的計測を行い精 度並びに適応性を調査した。固体物体に対しては，図-3に 


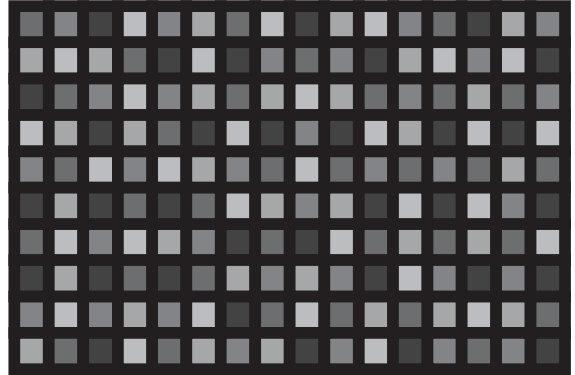

図-2 投影するカラーパターン (赤, 緑, 青, マゼンタ, シア ンの5色で色分けされる)

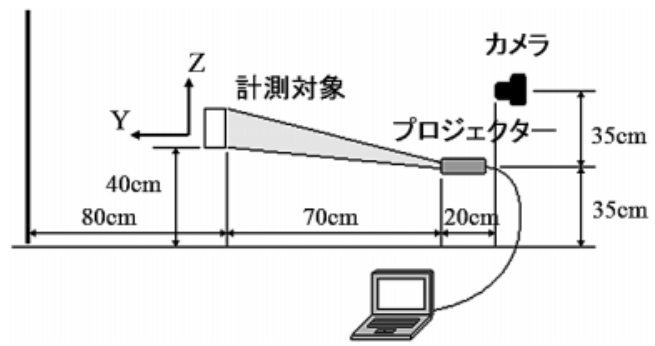

図-3 固体表面計測に対する実験装置の構成

示すように，プロジェクター（解像度 $1024 \times 768$, 輝度 3000 ルーメン）の約 $20 \mathrm{~cm}$ 後方, $35 \mathrm{~cm}$ 上方にカメラ（解像 度 $1600 \times 1200 ）$ を設置し，プロジェクターの約 $70 \mathrm{~cm}$ 前方 に対象物体を設置し，3次元形状計測を行った。キャリブ レーションは対象物体の前後， $15 \mathrm{~cm}$ 間隔で較正用格子を 設置して行った，液体の自由水面計測では，延長 $8 \mathrm{~m} ，$ 幅 $25 \mathrm{~cm}$, 高さ $40 \mathrm{~cm}$ の 2 次元造波水槽において, 進行波およ び水路内に設置した円柱状コンクリートブロック上を波 が通過する際の3 次元的な水面変形の計測を行った（図-4 参照). 水平床上の造波水槽上にカメラとプロジェクター を固定し，水深 $20 \mathrm{~cm}$ ，入射波高 $5 \mathrm{~cm}$ ，周期 0.8 秒の波浪に ついて実験を行った．動画像の撮影は30fpsで行った。同 一条件の波を $12 \mathrm{~cm}$ 間隔で設置した 2 本の容量式波高計に より計測し，本計測法による計測結果との比較を行う。な お，水は透過率が高いため，水面に投影したカラー座標 は水面で反射せず，そのままでは撮影ができない。本実 験では, 水路内の水に溶解性微粉末を混入し, 白濁させ て反射率を増加させ計測を行った。

\section{4. 結果}

\section{（1）固体表面計測}

図-5は，100×60×200mmの直方体コンクリートブロ ックにカラーパターンを照射し, 計測された 3 次元表面座 標をプロットし，実測值と比較したものである，なお，力 ラーパターンが撮影されている領域のみに対して座標化 されるため, ブロックの $2 つ の$ 側面の形状が座標化されて いる. それぞれのカラーパターンに対応する点について

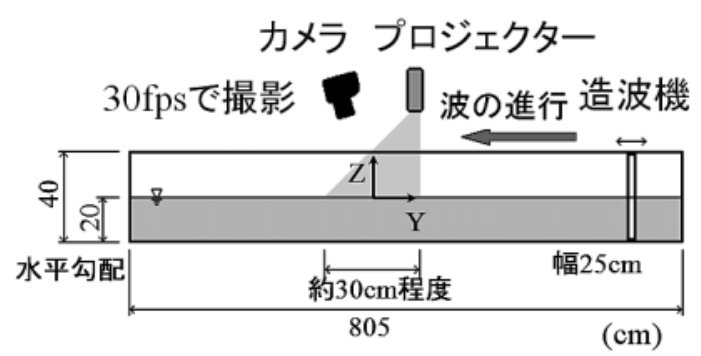

図-4 自由水面計測に対する実験装置の構成

(a)

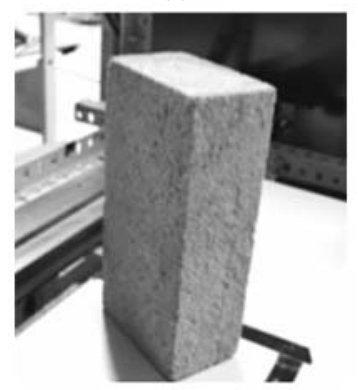

(c)

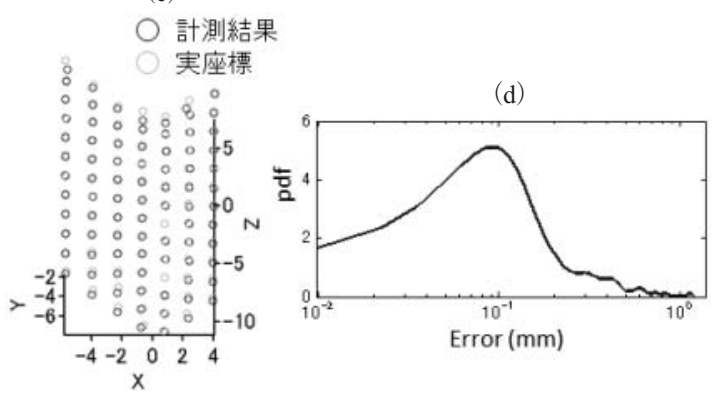

図-5 コンクリートの直方体ブロック (a), 計測時の撮影画像 (b). 計測結果 (c, 単位： $\mathrm{cm}$ ) と誤差の確率密度分布 (d)

ブロック上の座標を実測したものと比較すると若干差異 がある点も存在するが, 適切に直角に交わるブロック側 面の表面形状が計測されていることがわかる．実測值と 本計測法による計測值の差の確率密度分布から, 誤差ピ ークは約 $0.09 \mathrm{~mm}$, 最大誤差は約 $0.4 \mathrm{~mm}$ と本計測法の高い 精度を確認することができる。

前述のように本計測法はカラーパターンが撮影されて いる表面のみ座標化を可能とするが，同一物体を物体の 背後から撮影し座標を合成することで，物体全面の座標 を取得することができる。図-6は，模型テトラポッドを $120^{\circ}$ ずつ視軸を回転させて 3 方向から撮影し，座標を合 成した結果をプロットしたものである。ブロックのゆる やかな曲面が連続的に変化する独特の形状を適切に再現 しているのがわかる。図-7は, 模型六脚ブロックに対し て同様に計測し，ブロックの全面の形状を再構成したも のである. 全ての面について正しく計測され，座標の合 成が行われていることがわかる。 

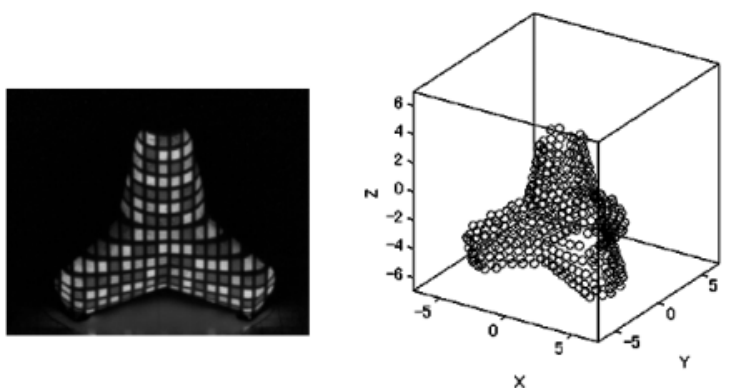

図-6 模型テトラポッド計測時の撮影画像（左）と計測結果 (右). 単位 : $\mathrm{cm}$.
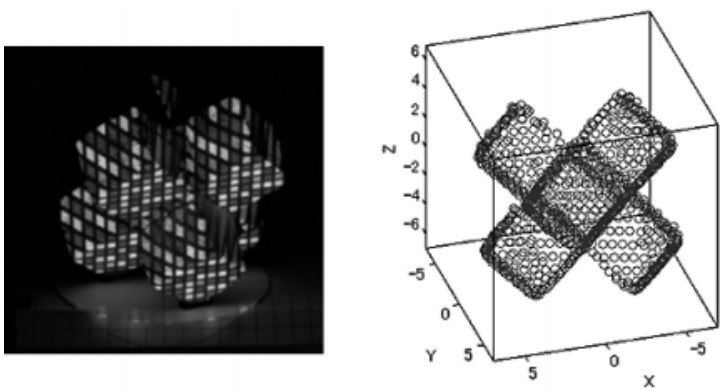

図-7 模型六脚ブロック計測時の撮影画像（左）と計測結果 (右). 単位： $\mathrm{cm}$.

さらに複雑な形状をもつ構造物に対しても適切に表面 座標の数值化が行われ良好な結果を得ることができる. 図-8は，テトラポッドを二層整積した模型消波堤を撮影 した原画像と計測した表面座標をプロットしたものであ る.なお，複雑な形状を認識し易い様に鉛直座標に比例 するグレイスケール濃度でプロットを表している。ブロ ックの影になり照明が到達しない空隙内の座標化はでき ないため欠測箇所が存在するが，それ以外の構造物の外 表面についてはブロックの重なりや詳細な組み合わせを 良く座標化できているのがわかる。この計測システムに より室内での消波構造物の安定実験等において，波浪に よるブロック飛散や変形の数值的な評価を可能とし，そ の性能の詳細な定量的検討を実現できる.

\section{(2) 自由水面計測}

本計測システムは，カラーパターンが照射された計測 領域を動画撮影することで，動的に物体の三次元形状を 追跡可能である。さらに，液体についても照明の水中へ の透過を阻止し水面近傍で反射させることができれば，動 的に自由水面形状を計測できる。図-9は，溶解性白色粉 末で水を白濁させた進行波の水面形を計測した結果であ る. 動的な自由水面の変動が数值化され，水路横断方向 に一様な典型的な微小振幅波形が取得されていることが, 波速を基に各位相の座標を空間的に合成した結果からわ かる (図-9 (e) 参照).

図-10は，計測領域中央における水位変化の時系列と容

(a)

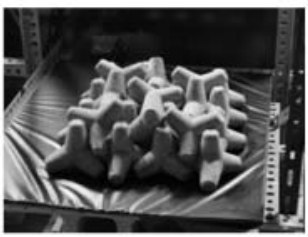

(c)

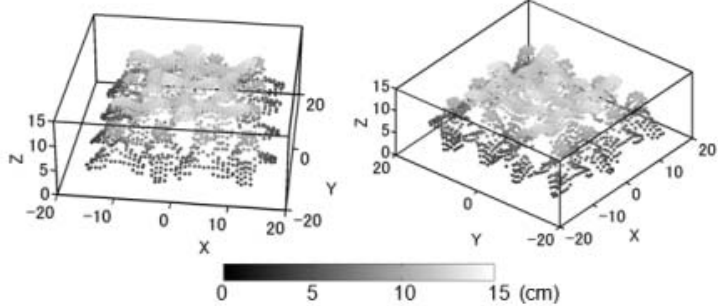

図-8 模型テトラポッド2層整積消波堤（a）と計測時の撮影画 像（b)．異なる角度に対する計測結果のプロット（c) (d). 単位 : $\mathrm{cm}$

(a)

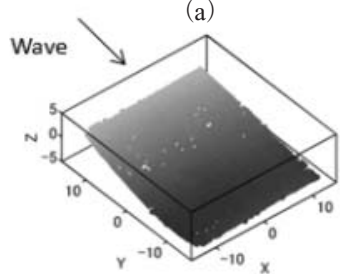

(c)
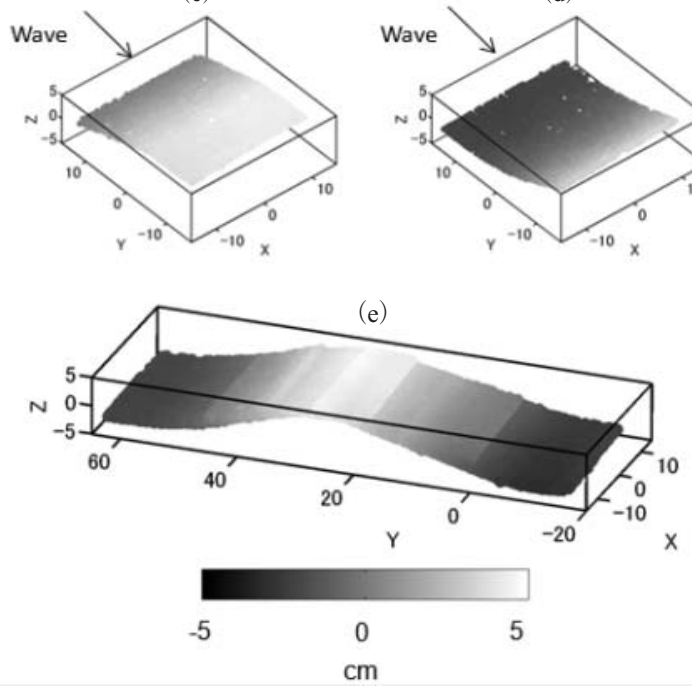

図-9 造波水槽中の進行波の計測結果（a）（b）（c）（d）：0.13s 間隔. 計測座標の合成による進行波形状の再現 (e). 単 位： $\mathrm{cm}$

量式波高計によって計測されたそれとを比較したもので ある．両者は概ね一致しているが，位相によって最大 $5 \mathrm{~mm}$ 程度の差異が確認された。これは，カラーパターン照明 の白濁した水中への透過深と一致しており，照明が完全 に水面で反射されていないことに起因するものであり，本 


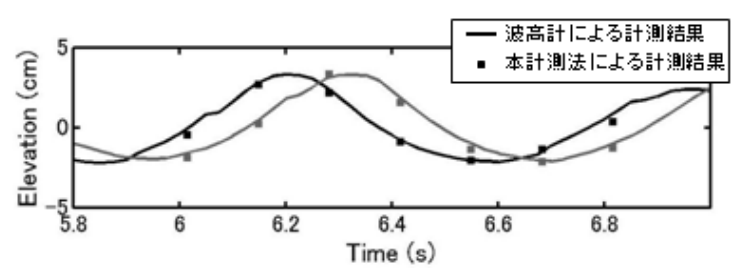

図-10 波高計で計測された水位変動と本計測法との比較

計測システムの直接的問題ではなく, 混入粉末あるいは 染料を変更するなど撮影媒体の透過率を低減することで 誤差を隇少させることができると考える。

水面の光の透過に起因するある程度の誤差を許容した 上で, 三次元的な波浪の自由水面変形の時間変化を計測 し，本計測法による面的波浪計測の可能性を調查する。 図-11 は, 二次元造波水槽の中央に高さ $20 \mathrm{~cm}$ 直径 $10 \mathrm{~cm}$ の コンクリート円柱を設置し, その周辺の空間的水位変動 を計測したものである. 進行波の波峰が通過後に同心円 状に放出される典型的な円筒波が軸対象に伝達している 様子が計測されているのがわかる. 瞬時の平面的水位変 動を計測する手段が他にないため, 計測結果の精度を検 討することはできないが, その変動の特徵は合理的であ り適当に水路横断方向に変化する水面形状の数值化がさ れているものと考える.

本計測法は, 光の透過に係る誤差は生じるものの, 瞬 時の面的な水位変動を計測できるため, 屈折, 回折を含 む多様な面的波浪状況を時々刻々定量的な評価を可能と するものであり, 平面水槽実験における静穏度評価や構 造物近傍の局所波浪変形の定量化, 数值計算結果との照 合, 精度評価など多様な研究に利用できるものと考える. なお動的計測において, 瞬時の投影カラーパターンを撮 影できれば，原理的には任意の速度で移動する物体ある いは液体に適応可能である一方, 高速移動する対象に対 しては短時間のシャッタースピードで撮影する必要があ り, これに応じた高出力のプロジェクタが必要となるで あろう。

\section{5. 結論}

本研究で開発した物体の3次元表面座標計測法は, プロ ジェクター照明が照射された物体を撮影した 1 枚の画像か ら精度良く表面座標を計測するものであり, 従来のステ レオグラム法の使用制約がない応用性, 信頼性の高いも のである．表面座標が既知である直方体ブロックを対象 とした計測誤差は $0.09 \mathrm{~mm}$ であり，高精度で計測を行える ことが明らかになった。
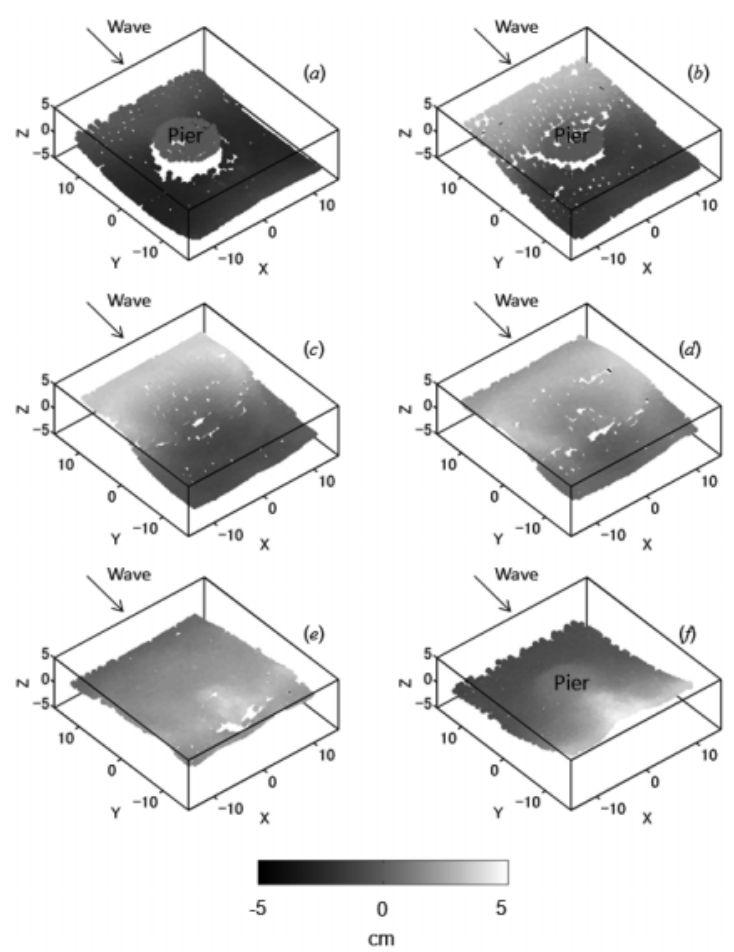

図-11 進行波がコンクリート円柱を過る時の水面形計測結果. 単位 $: \mathrm{cm}$

本計測法では, 計測により得られる物体の表面座標を 同一物体の背後から計測を行うことで得られる座標と合 成することで，その物体全体の表面形状を取得できる. 模 型テトラポッドおよび模型六脚ブロックの計測により, 曲 面やエッジを有する物体に対しても表面全域の座標を正 確に計測可能であることを確認した。また，模型テトラ ポッド2層整積消波堤に対して計測を行い, ブロックが重 なり合う非常に複雑な形状を持つ構造物に対して表面座 標の数值化が適切に行われることを確認した. 本計測法 により様々な構造物の変形や移動を数值的に評価するこ とが可能であり, 消波構造物の安定実験等多様な実験や 調查への適用が可能である.

造波水槽中の進行波の計測から, 本計測法の動的な波 面計測への適用性と信頼性を確認した。本計測法では波 と構造物の相互作用等による多様な面的水位変動を動的 に計測することが可能であり, 様々な研究への適用が可 能である。

\section{参 考 文 献}

徐 剛・过 三郎 (1998)：3次元ビジョン, 共立出版, 181p. 